\title{
A formação de hábitos e a origem das leis na VII Conferência de Cambridge, de Ch. S. Peirce
}

\section{The Formation of Habits and the Origin of Laws in the Cambridge Conference VII, by Ch. S. Peirce}

*Ivo Assad Ibri

\begin{abstract}
Resumo: O presente artigo reflete sobre os argumentos propostos por Charles Sanders Peirce em sua conhecida VII Conferência de Cambridge, proferida em 1898, sob o título "Hábito", na qual justifica a sua posição acerca de como seria possível explicar a origem do universo através de uma filosofia de caráter genético. Essa explicação toma, no interior de seu complexo sistema arquitetônico de pensamento, a tendência à aquisição de hábitos como o princípio explicativo fulcral sobre a origem e a evolução das Leis da Natureza. Peirce adota tal princípio como aquele que sustentaria uma afinidade entre mente e matéria.

Palavras-chave: Peirce. Hábito. Conservação da energia. Acaso. Origem das leis naturais.
\end{abstract}

Abstract: This article aims a reflection on the arguments proposed by Charles Sanders Peirce in his well-known Cambridge Conference VII, issued in 1898, under the title "Habit", in which he justifies his position about how it would be possible to explain the origin of the universe through a philosophy with a genetic character. This explanation takes, within his complex architectural system of thought, the tendency of acquiring habits as the axial explanatory principle of the origin of Laws of Nature. Peirce takes such a principle as the basis on which it would be possible to claim an affinity between mind and matter.

Keywords: Peirce. Habit. Conservation of Energy. Chance. Origin of Laws of Nature.

\footnotetext{
* Professor Titular de Filosofia na Pontifícia Universidade Católica de São Paulo (PUC/SP - Brasil). Presidente da Charles Sanders Peirce Society - EUA, (2014-2015). <ibri@uol.com.br>.
} 
A VII Conferência de Cambridge, com o título "Hábito", proferida 1 por Charles Sanders Peirce em 1898, é, sem dúvida alguma, um rico ponto de partida para se discutir facetas interessantes do seu pensamento. Neste ensaio, busco destacar os elementos conceituais mais importantes da referida Conferência, com ênfase em elementos que podem ser arrolados mediante a remissão ao sistema filosófico do autor, que enuncia já nas primeiras páginas da Conferência o seu tema seminal, a saber, que "causação, enquanto distinta da ação da força conservativa, é um elemento real, fundamental e vital, tanto no mundo externo quanto no interno". De fato, a Conferência está estruturada para explicar e fundamentar o sentido mais agudo expresso por essa proposição, passando por exposições conceituais com apelo a ciências como a física, a matemática e as disciplinas da filosofia, a exemplo da fenomenologia e da metafísica. O seu objetivo era explicar a origem das leis do universo por meio da tendência à formação de hábitos. Assim, abordarei, sinteticamente, os argumentos fundamentais usados pelo autor no texto e proporei, ao final, questões para reflexão que creio que dão continuidade especulativa ao conceito de hábito, tão relevante para os estudiosos da obra de Peirce.

\section{Uma pergunta fundamental}

Na VII Conferência de Cambridge ${ }^{1}$, Peirce formula uma pergunta fundamental, cuja resposta torna-se essencial ao que ele pretende expor como hipótese explicativa sobre a origem das Leis da natureza: "[...] Haveria um método de raciocínio pelo qual poderíamos nos assegurar de que qualquer Lei que se possa descobrir pela observação da Natureza [...] nela representaria uma ação viva e real?"2. Para os estudiosos da obra peirciana e, mais especialmente, para aqueles dotados de uma visão sistêmica de sua filosofia, da qual não poderia estar ausente a sua ontologia de maturidade, a resposta a essa pergunta seria claramente positiva. A conferência desenha-se, em suas linhas gerais conceituais, na direção de mostrar por que tal resposta seria, então, positiva. Sem dúvida, a leitura do texto da conferência explicita o método lógico e pragmático empregado pelo autor, examinando sempre as consequências dos conceitos e das hipóteses com os quais trabalha esse problema geral ${ }^{3}$.

1 Cf. PEIRCE, Charles Sanders, Reasoning and the Logic of Things. The Cambridge Conferences of 1898, Cambridge, Mass.: Harvard University Press, 1992. A partir daqui, RTL...

2 Id. ibid., p. 219.

3 Id. ibid. 
Trata-se do método que, em outra ocasião, busquei evidenciar na concepção do edifício metafísico do autor ${ }^{4}$.

\section{Sobre a lei da conservação da energia e as ações não-conservativas}

Peirce vale-se das explicações propostas pelos físicos de sua época para os fenômenos irreversíveis, a saber, aquelas que fazem recurso à doutrina dos acasos aplicada a trilhões de moléculas. No entanto, o seu enfoque terá por eixo o realismo dos continua, tal qual adota na sua obra madura, e essa postura filosófica terá, por consequência, uma teoria da realidade que concebe as leis como fatos reais e não como meras fórmulas teóricas oriundas de abstração de fatos particulares, tal qual propugnam filosofias de cunho nominalista ${ }^{5}$. À luz dessa postura filosófica, Peirce afirma que as ações não-conservativas, que parecem violar a lei da conservação da energia, são marcadas por duas características: (a) elas agem em uma determinada direção e, assim, tendem, assintoticamente, a trazer à tona um estado último de coisas, característica que pode ser chamada de característica "teleológica" ou "finista" (finious); (b) elas são irreversíveis ${ }^{6}$.

A reflexão sobre esse tema prossegue considerando o modo de ser das ações não-conservativas, que, em conjunto com as leis conservativas, configuram uma evidência de que as Leis não devem ser tomadas como perfeitamente gerais, em seu estágio último de evolução, mas que elas envolvem, também, certas violações, por pequenas que sejam, associadas ao surgimento de elementos discretos no continuum da lei. Nessa linha de análise, Peirce afirma: "Se determinado evento [um evento nãoconservativo] pode ocorrer, então segue-se como uma consequência necessária que existe algo como um evento absolutamente aleatório"7. Segundo ele, somente o reconhecimento da interferência de um princípio real de Acaso, introduzindo elementos discretos à margem do continuum da Lei, pode explicar a irreversibilidade dos fenômenos. O Acaso, tomado como mera probabilidade, portanto, em uma concepção nominalista, falha, por essa razão, em explicar tal reversibilidade. Na verdade, para Peirce, os fenômenos não-conservativos são evidências reais da presença e não da ausência do acaso real, pois " [...] mesmo uma variação

4 Cf. IBRI, Ivo Assad, Kósmos Noetós: a arquitetura metafísica de Charles S. Peirce, São Paulo: Perspectiva - Hólon, 1992, Capítulo 6.

5 Id. ibid., Capítulo 2. Cf. também MAYORGA, Rosa M., From Realism to "Realicism". The Metaphysics of Charles Sanders Peirce, Lanham: Lexington Books, 2007, p. 5-37.

6 Cf. $R L T$, p. 220.

7 Id. ibid., p. 223. 
infinitesimal nas condições [do fenômeno] produzirá uma diferença finita no resultado [fático]"8.

\section{Realidade e desvio nas Leis}

No âmbito da temática da VII Conferência, nasce a questão se haveria ou não, objetivamente, desvios nas Leis. Tal questão pode apenas ser decidida, segundo Peirce, pela consideração de que "[...] deve ter havido algum processo lógico na Natureza pelo qual as suas Leis tiveram origem"9. É conhecida a máxima lógica de Peirce que afirma que não podemos supor uma hipótese que "bloqueie o caminho da investigação"10 e tal seria o caso se simplesmente se afirmasse as Leis como fatos dados e inexplicáveis, presentes desde o início do cosmo, exatamente da maneira como atuam hoje. Tampouco se permitiriam adotar soluções criacionistas, sob pena de indevidamente sobrepor-se a metafísica à lógica, procedimento definitivamente banido pela filosofia de Kant ${ }^{11}$. Refletir, então, sobre a origem das Leis conduz, necessariamente, à suposição de um processo evolucionário do qual elas se constituíram. Cumpre-se, aqui, não mais que a vocação da filosofia de Peirce para se propor genética, a saber, de poder oferecer hipóteses lógicas para a gênese não apenas de aspectos da realidade, mas, também, de teorias sobre ela. Recordem-se as considerações sobre a origem das hipóteses, de como novas ideias surgem na direção de se encontrar teorias verdadeiras, desenhando o que se denomina lógica da descoberta ou lógica heurística, mais conhecidas como lógica da abdução ${ }^{12}$.

\section{Tipos de associações de ideias}

Na sequência da Conferencia VII, um breve hiato na solução da questão sobre a origem das Leis possibilita refletir sobre os modos como se dão as associações de ideias. De acordo com Peirce, tais associações seriam de dois tipos:

8 Ibid.

9 Ibid.

10 Ibid. Cf. também PEIRCE, Charles Sanders, Collected Papers of Charles Sanders Peirce, edited by Charles Hartshorne, Paul Weiss, and Arthur W. Burks, Cambridge, Mass.: Harvard University Press, 1931-1935 e 1958, 1.135. A partir daqui CP...

11 A primeira Crítica de Kant, a par de sua epistemologia negativa, exibe quase ubiquamente os erros da inversão de dependência entre lógica e metafísica. Cf. KANT, Imannuel, The Critique of Pure Reason, edited [and translated] by Paul Guyer and Allen W. Wood, Cambridge: Cambridge University Press, 1998.

12 Cf. IBRI, Ivo Assad, The Heuristic Exclusivity of Abduction in Peirce's Philosophy, in: LEO, Rossella Fabbrichesi and MARIETTI, Susana (eds.), Semiotics and Philosophy in C. S. Peirce, Cambridge: Cambridge Scholars Press, 2006, p. 90-112. 
(1) haveria uma disposição natural da mente para o que poderia ser denominado "associações por semelhança". Tal tipo de associação de ideias pode ser chamado de uma "ideia geral"13. Uma ideia geral é a marca de um hábito; a repetição de tal ideia geral e a experiência da sua eficiência prática resulta na formação ou no fortalecimento do hábito que lhe corresponde e que, nesse sentido, se torna uma concepção.

(2) por meio de um hábito adquirido pela mente, no sentido de que ideias similares são conjugadas na experiência até que elas se tornem associadas; esse tipo de associação de ideias equivale à "associação por contiguidade".

À luz desses modos de associação de ideias, Peirce especula sobre o que seria uma ação mental? Ele entende ser plausível supor que ações mentais operam por associação de ideias, havendo cinco características importantes a serem observadas no que se refere a tais ações, a saber:

(i) uma ideia considerada em si mesma não retém temporalmente a sua vivacidade, tendendo a tornar-se gradativamente mais esmaecida, obscura ${ }^{14}$.

(ii) ideias associadas na consciência passam por alterações de vivacidade ${ }^{15}$.

(iii) a ação da sugestão associativa não ocorre instantaneamente, ou seja, tão logo duas ideias são associadas; apenas quando o Acaso atua como conexão acidental de duas ideias uma pode agir sobre a outra ${ }^{16}$.

(iv) a variação de vivacidade é acompanhada por outro evento que ocorre em conjunção, como experiência externa, embora haja dela um signo na consciência ${ }^{17}$. Em outros termos, a associação entre duas ideias se reforça pela ocorrência de tal experiência, de modo que uma ideia mais vívida se torna mais suscetível de trazer à tona ideias menos vívidas em outras ocasiões ${ }^{18}$.

(v) enquanto algumas ideias são revivescidas pela experiência, certas outras associações se enfraquecem pela ausência desse processo revivenciador ${ }^{19}$.

Sob essas considerações, Peirce propõe a questão crucial: seriam as ações mentais ou psíquicas, tais como descritas anteriormente,

\footnotetext{
13 Cf. $R L T$, p. 234.

14 Id. ibid., p. 236.

15 Ibid., p. 236.

16 Ibid.

17 Ibid., p. 237.

18 Ibid.

19 Ibid.
} 
conservativas ou não-conservativas? Como resposta, afirma ele ser evidente que não há reversibilidade nas ações mentais, exibindo elas duas características essenciais, ou seja, a de serem teleológicas e irreversíveis ${ }^{20}$. Vejamos o que tais características irão importar para a sequência temática dessa Conferência, passando antes pela questão genética cuja resposta será uma hipótese explicativa sobre a origem das Leis da Natureza.

\section{Sobre a origem das Leis da Natureza}

A nossa curiosidade científica é estimulada no mais alto grau pelas notáveis relações que descobrimos no interior das diferentes Leis da Natureza. Essas relações clamam, no ver de Peirce, por uma explicação racional $^{21}$. Para encontrar tal explicação, de acordo com os princípios estritos da lógica, devem-se deduzir as leis fundamentais do universo físico como consequências necessárias de alguma hipótese ${ }^{22}$. Fosse, contudo, essa questão referida apenas à forma das leis, dever-se-ia almejar tão-somente uma explicação puramente formal, tal como a adotada por Hegel, por exemplo. Peirce, todavia, é enfático ao afirmar não ser suficiente uma mera explicação formal, uma vez as Leis da Natureza envolverem e serem afetadas de constantes puramente empíricas ${ }^{23}$. Essa linha de argumentação que descarta a suficiência de uma dedução simplesmente teórica, acaba conduzindo a resposta à questão a uma hipótese de natureza ontológica, a saber, supondo um processo pelo qual as leis evolveram de um processo evolucionário:

Podemos supor que as leis da Natureza sejam resultados de um processo evolucionário. [...] Mas, se as leis da Natureza são resultados da evolução, esse processo evolucionário deve ser suposto ainda em curso. Pois, ele não pode estar completo na medida em que as constantes das leis não tenham atingido qualquer possível limite último ${ }^{24}$.

É interessante observar que a constatação de que as constantes das leis não são, de fato, constantes, mas envolvem variações que denotam não terem atingido valores últimos, impede que se suponha a questão meramente de forma, caso em que se teria a esperança de buscar soluções formais mais complexas que dessem conta da forma real atuante nos fenômenos. Exemplarmente, e tomando-se um caso formalmente simples,

\footnotetext{
20 Ibid., p. 237-238.

21 Ibid., p. 239.

22 Ibid.

23 Ibid., p. 240.

24 Ibid.
} 
suponha-se uma variação linear entre duas grandezas físicas, tal como ocorre elementarmente entre calor fornecido a uma substância e as variações de temperatura então decorrentes. Sob o ponto de vista formal, é evidente que a idealidade de uma reta passa apenas por um conjunto de medições em torno dela, desde que ela seja resultado de ajuste estatístico, digamos, pelo método dos mínimos quadrados, por exemplo. A pretensão de se encontrar uma curva de um polinômio complexo de grau definido que contivesse todos os pontos resultados das medições, seria a seu tempo frustrada. A reta ajustada evidenciaria ser a melhor solução, e a sua inclinação, dada pela constante empírica multiplicadora do calor fornecido, teria uma variação não dedutível de qualquer modelo teórico, generalizando-se essa conclusão para qualquer função polinomial de grau superior a um, como é o caso do exemplo linear que se adotou.

É também importante ressaltar que desvios não são exceções a uma regra exata, numa espécie de expectativa determinista sobre os fenômenos. Constituem, de fato, a expressão ontológica do modo como a lei é aproximada às réplicas oriundas de observações e medições. Não obstante essas observações não constarem propriamente da Conferência em foco, parece ser elucidativo mencioná-las, no auxílio à compreensão do que afirmara Peirce a respeito das constantes das leis.

Retomando o argumento de Peirce, considere-se, então, que estando as Leis da Natureza ainda em processo evolucionário, tendo por origem um estado de coisas no infinitamente distante passado no qual não havia leis, conclui-se que os eventos não são, mesmo agora, absolutamente regulados pela lei ${ }^{25}$. A natureza ontológica dos desvios das leis não pode ser reduzida a uma mera questão epistemológica, cujo fundamento estaria na consideração de que um aperfeiçoamento e aprofundamento dos métodos de investigação eliminariam aqueles desvios, reduzindo-os, portanto, a meros erros de observação. Essa linha de argumentação lastreia-se em uma espécie de esperança determinista que fenomenologicamente não tem qualquer suporte - basta perceber o grau de irregularidade e assimetria dos fatos naturais ${ }^{26}$. A adoção de um indeterminismo ontológico, com a admissão de um princípio real de Acaso, vem eliminar essa esperança e coaduna-se melhor com o que se observa na Natureza. Como consequência epistemológica dessa admissão de um princípio de aleatoriedade ativo nos fenômenos, tem-se a doutrina peirciana denominada "falibilismo", afirmando que todas as nossas teorias fáticas são falíveis ${ }^{27}$ e que não se pode pretender graus

\footnotetext{
25 Ibid.

26 Cf., por exemplo, CP, 6.60 e CP, 7.189.

27 Cf. Cf. IBRI, Ivo Assad, Kósmos Noetós: a arquitetura metafísica de Charles S. Peirce, Capítulo 3.
} 
últimos de certeza acerca de objetos que não se encontram estritamente sob leis acabadas. As Leis, interagindo com o Acaso, dotam o mundo de uma ordem parcial, incompleta.

A argumentação a favor do Acaso tem um suporte além do imediatamente fenomenológico, onde a assimetria dos fatos coabita com a sua parcial simetria. A constatação de que os fenômenos naturais são irreversíveis presta-se a se constituir como apoio cabal a favor da admissão da hipótese de um princípio de aleatoriedade neles interveniente. De fato, parece ser simples visualizar que uma lei exata, regrando de modo estrito todas as réplicas sob ela, se constituiria em uma forma precisa pela qual o retorno a um ponto de origem do fenômeno seria possível, em uma espécie de caminho de volta. Todavia, a interação com o Acaso "abre" essa forma ideal criando muitos caminhos sem volta. Afora as tecnicidades do tema e da sua argumentação, a sua visualização fática poderia se dar mediante um fantástico quadro imaginário constituído por uma sequência temporalmente invertida, qual um filme passado de trás para diante, em que pudéssemos ver uma árvore, por exemplo, com toda a assimetria que constitui a sua copa, a forma de seu tronco e de suas raízes, que não pode, a propósito, ser fruto de Lei, retroagir ao estado de semente de onde se originou. Fosse a sua história um fluxo espácio-temporal pelos canais de uma forma perfeita, esse retorno deveria ser pensado como possível. A par da irreversibilidade, tem-se a não-conservação da energia.

\section{Hábitos como origem das leis físicas e psíquicas}

A partir da conclusão de que as Leis da Natureza são o resultado da evolução, Peirce conjetura que tal evolução deva decorrer de acordo com algum princípio: "[...] Esse princípio deve ser da natureza de uma Lei" ${ }^{28}$. E prossegue: "ele deve ser uma lei que pode evolver-se por si mesma [...]"29. O problema se torna, então, o de descobrir se existe qualquer lei ou tendência que possuiria o poder de reforçar a si mesma, ou seja, uma tendência em direção à generalização, que se manifeste na Natureza a ponto de se fazer conhecida objetivamente. Onde devemos procurar por tal tendência? Certamente em nenhum lugar onde não haja nada de irregular, como a gravidade, por exemplo, mas sim onde a plasticidade e a evolução ainda estão em ação ${ }^{30}$. E Peirce arremata:

\footnotetext{
${ }^{28}$ Cf. $R L T$, p. 241.

29 Id. ibid.

30 Ibid.
} 
A mais plástica de todas as coisas é a mente humana, após a qual estaria o mundo orgânico, o mundo do protoplasma. Segue-se que a tendência à generalização é a grande lei da mente, a lei da associação, a lei de aquisição de hábitos. [...] Por conseguinte, sou levado à hipótese de que as leis do universo têm sido formadas sob a tendência universal de todas as coisas à generalização, à aquisição de hábitos ${ }^{31}$.

Em verdade, esse argumento aproxima a mente humana da Natureza. Ambas partilham a tendência à generalização, à aquisição de hábitos, e essa conclusão é simplesmente pragmática, na medida em que se sustenta no modo como se conduzem. Às ações mentais irreversíveis e, portanto, não mecânicas em um sentido determinista correspondem processos naturais que, por tendência à aquisição de hábitos, constituem as Leis que os enformam. Tais leis são regras de conduta cuja plasticidade no mundo orgânico faz com que certos hábitos sejam quebrados em face da atuação do Acaso. Permite-se, então, supor como plausível uma conaturalidade entre mente humana e Natureza que não deve ser estranha àqueles estudiosos da metafísica de Peirce que constataram a universalidade das categorias do autor, a sua validade indiferenciadamente fenomenológica, epistemológica e ontológica.

\section{Para reflexão futura}

A VII Conferência das assim chamadas Conferências de Cambridge de 1898, denominada "Hábito", traz muitos pontos conceituais para futura reflexão e desenvolvimento teórico, correlacionando-os às demais doutrinas de maturidade do autor. A guisa de conclusão, seguem-se algumas delas:

(a) Os processos irreversíveis de todas as coisas, que são relativos à vida e ao crescimento, não podem ser explicados por leis mecânicas reversíveis e, assim, nenhuma lei absoluta seria operativa na Natureza. Esse é um caminho pelo qual, de modo original, Peirce introduz o conceito de Acaso como um princípio necessário que faz o universo ser ontologicamente indeterminado e, consequentemente, toda a ciência de algum modo falível ${ }^{32}$.

(b) A tendência universal de aquisição de hábitos instaura e sustenta uma tese anticartesiana, a saber, de que não há, de gênese, qualquer dualidade ontológica entre mente e matéria. Partilhar aquela tendência faz com que se possa afirmar uma conaturalidade

31 Ibid.

32 Para uma perspectiva diferente acerca do falibilismo do autor, cf. MARGOLIS, Joseph, Rethinking Peirce's Fallibilism, in: Transactions of the Charles S. Peirce Society, 43:2 (2007), p. 229-249. 
entre mente e matéria, mediante uma análise pragmática que dá sentido a essa afirmação, a saber, baseada nas similaridades de conduta. É essa a linha mestra de pensamento que permite sustentar a doutrina peirciana do Idealismo Objetivo. Ela irá afirmar que essa natureza partilhada é eidética e não material - o materialismo levaria a um determinismo fisicalista ${ }^{33}$, e a sua recusa conduz à adoção de um Idealismo Objetivo como teoria de fundo ontológico.

(c) São formuláveis questões suficientemente provocativas, malgrado sem respostas no curto espaço desse ensaio, para o prosseguimento da reflexão ensejada pelo tema da VII Conferência: por que haveria essa tendência à aquisição de hábitos? Qual afinal seria a sua função? Pode-se, ao menos, afirmar que tais questões têm resposta possível no interior do sistema teórico de Peirce e que a VII Conferência traz novos elementos que enriquecem a sua solução.

(d) Evidenciam-se consequências decorrentes do Idealismo Objetivo tal qual aqui formulado, cuja exploração é também proibitiva no presente texto. A extensionalidade ontológica do conceito de mente do homem à Natureza impõe que se desenvolva uma filosofia não mais antropocêntrica. Um caráter universalmente mental, em todas as suas manifestações, deverá ser encontrado nos processos naturais. Não será mais surpreendente para os estudiosos dessa filosofia o espanto dos cientistas com a inteligência dos seres naturais em seus diversos reinos, nem tampouco a capacidade heurística de tais seres de dialogar semioticamente com o seu meio e, sempre que necessário, os modificar seus hábitos, como mostra abundantemente a História Natural e a Evolução ${ }^{34}$. Esses mesmos estudiosos entenderão melhor, talvez, os artistas, que ao longo da história reconheceram nas qualidades sensíveis, presentes no espetáculo da Natureza, um móbile de sentimentos, com base em que produziram a mais refinada arte ${ }^{35}$. Por fim, a quebra do dualismo mente-matéria, rompe de vez um estranhamento de gênese entre homem e Natureza de há muito vigente em nossa cultura e, pode-se conjeturar, também responsável pela

${ }^{33}$ Cf. IBRI, Ivo Assad, Kósmos Noetós: a arquitetura metafísica de Charles S. Peirce, Capítulos. 3 e 4.

34 Cf. IBRI, Ivo Assad, The Continuity of Life: On Peirce's Objective Idealism, in: ROMANINI, Vinicius and FERNÁNDES, Eliseo (eds.), Peirce and Biosemiotics: A Guess at the Riddle of Life, Dordrecht - Heidelberg - New York - London: Springer, 2014, p. 33-49.

35 Sobre esse tema, cf. IBRI, Ivo Assad, Reflections on a Poetic Ground in Peirce's Philosophy, in: Transactions of the Charles S. Peirce Society, 45:3 (2009), p. 273-307. 
transformação radical do mundo natural e pela sua indiscriminada exploração. Poder-se-ia perguntar se filosofias antropocêntricas, muitas, não obstante, formuladoras de brilhantes insights e se posicionando como humanistas, não justificaram de modo oblíquo aquele estranhamento e a perigosa inviabilização do ambiente natural para a vida humana.

Uma filosofia teoricamente rica e heurística como a de Peirce permite repensar muitas questões mantendo-se um elemento comum em sua base: o caráter evolucionário presente no eixo teórico de seu pensamento ${ }^{36}$. Com base nele, todos os seres do universo partilham uma mesma origem, e esse fato sustenta a construção de uma filosofia genética, tal como propôs Schelling ${ }^{37}$, condicionando hipóteses explicativas que irão propor sistemas complexos de relações, plausíveis pelo comércio semiótico facultado pela conaturalidade ontológica de seus protagonistas.

\section{Referências}

ESPOSITO, Joseph. Evolutionary Metaphysics. The Development of Peirce's Theory of Categories. Athens: Ohio University Press, 1980.

HAUSMAN, Carl R. Charles S. Peirce's Evolutionary Philosophy. New York: Cambridge University Press, 1993.

IBRI, Ivo Assad. Kósmos Noetós: a arquitetura metafísica de Charles S. Peirce. São Paulo: Perspectiva - Hólon, 1992. Obra revista e atualizada, reeditada in: São Paulo: Editora Paulus, 2015.

. Reflections on a Poetic Ground in Peirce's Philosophy. In: Transactions of the Charles S. Peirce Society, 45:3 (2009), p. 273-307.

. The Continuity of Life: On Peirce's Objective Idealism. In: ROMANINI, Vinicius and FERNÁNDES, Eliseo (eds.). Peirce and Biosemiotics: A Guess at the Riddle of Life. Dordrecht - Heidelberg - New York - London: Springer, 2014, p. 33-49.

. The Heuristic Exclusivity of Abduction in Peirce's Philosophy. In: LEO, Rossella Fabbrichesi and MARIETTI, Susana (eds.). Semiotics and Philosophy in C. S. Peirce. Cambridge: Cambridge Scholars Press, 2006, p. 90-112.

KANT, Imannuel. The Critique of Pure Reason. Edited [and translated] by Paul Guyer and Allen W. Wood (The Cambridge Edition of the Works of Immanuel Kant). Cambridge: Cambridge University Press, 1998.

MARGOLIS, Joseph. Rethinking Peirce's Fallibilism. In: Transactions of the Charles S. Peirce Society, 43:2 (2007), p. 229-249.

${ }^{36}$ Para outras e também interessantes abordagens acerca deste ponto, cf. HAUSMAN, Carl R., Charles S. Peirce's Evolutionary Philosophy, New York: Cambridge University Press, 1993; e ESPOSITO, Joseph, Evolutionary Metaphysics. The Development of Peirce's Theory of Categories, Athens: Ohio University Press, 1980.

37 Cf. SCHELLING, F. W. J., Ideas for a Philosophy of Nature, translation by Errol E. Harris and P. Heath, Cambridge: Cambridge University Press, 1988, p. 30. 
MAYORGA, Rosa M. From Realism to "Realicism". The Metaphysics of Charles Sanders Peirce. Lanham: Lexington Books, 2007.

PEIRCE, Charles Sanders. Reasoning and the Logic of Things. The Cambridge Conferences of 1898. Cambridge, Mass.: Harvard University Press, 1992.

Collected Papers of Charles Sanders Peirce. Edited by Charles Hartshorne, Paul Weiss, and Arthur W. Burks. Cambridge, Mass.: Harvard University Press, 19311935 e 1958. $8 \mathrm{v}$.

SCHELLING, F. W. J. Ideas for a Philosophy of Nature. Translation by Errol E. Harris and P. Heath. Cambridge: Cambridge University Press, 1988. 